\section{THE ENERGY POLICY ACT OF 2005: A MISSED OPPORTUNITY}

There is little doubt that energy is high on the agenda for Congress and the public, particularly after hurricanes Isabel in 2003, and, more recently, "Katrina" and "Rita" and the spurt in oil, natural gas, and gasoline prices. Everincreasing prices have prompted consumers to look to Congress and the President to work together to address our energy needs and to provide new energy alternatives. President Bush recognized this when he re-introduced his energy plan after it had been tabled during his first term. The legislation was amended and passed by both houses of Congress and signed into law on August 8, 2005, creating the Energy Policy Act of 2005 (“The Act”).

The Act is intended to be a comprehensive plan for future energy needs. It addresses the issue of supply by providing tax and other incentives for additional infrastructure and also encouraging development and support of alternative and renewable forms of energy. With respect to issues of demand, however, the Act primarily relies on energy efficiency as a means of control. For example, the Act provides $\$ 250$ million in consumer rebates for purchasing energy-efficient appliances, $\$ 874$ million for purchasing alternative fuel or hybrid vehicles, and $\$ 1.23$ billion in weatherization assistance. It also provides $\$ 450$ million for an energy efficiency education initiative and appropriations as may be necessary for public energy education programs. Unfortunately, the Act misses the opportunity to fundamentally address energy demand issues with less bureaucracy and less taxpayer dollars, using time-sensitive pricing for electric utilities. This issue is addressed, but only by asking states to consider the use of "smart metering" or time-sensitive pricing, without making it energy policy.

Time-sensitive pricing is a system where consumers who choose to use electricity during peak daytime hours pay a premium for power, while consumers who wait until offpeak times pay lower rates. Another form of such pricing is real-time pricing where price levels, time periods, and timing all vary as the cost of electricity varies.

According to the Annual Energy Outlook 2005 With Projections to 2025 published by the Energy Information Administration, demand for electricity is expected to increase approximately 50 percent from 2003 to 2025. With growing electricity demand and the retirement of inefficient, older generation capacity, 281 gigawatts of new capacity will be needed by 2025 . There also is a significant need for additional transmission lines. But the problem with simply building power plants and transmission lines (besides the "not in my backyard" syndrome) is that additional plants and lines, by themselves, are not a cost effective answer to electricity shortages.

\author{
Articles \\ Judicial and executive branches of government - \\ a new partnership?
}

News

\section{Articles (cont'd)}

Ombudsmen and administrative justice

Recent judicial and legislative developments

in the law of transfer of undertakings

The real cost of power changes continuously throughout the day. Yet, with only a few exceptions, customers see a flat price per kilowatt hour on their bills. They, therefore, have no incentive to reduce their consumption during periods and increase consumption in the off-peak periods. Under this traditional pricing method, building additional power plants and transmission lines will not necessarily ensure the availability of adequate electric supplies. The added costs of those facilities will simply be rolled into the existing cost structures of electric suppliers, and the costs will be passed on to consumers in their monthly bills. Consumers will continue to demand greater amounts of electricity at peak periods, and more plants and lines will be built to meet those demands instead of ensuring better utilization from existing plants and lines.

There is little doubt about the need for additional capacity, but equally without doubt is the need for time-sensitive rates. Absent a motive to adjust time of day use, electricity grids hit huge usage peaks in the late afternoon and early evening, with usage levels tapering off to a small fraction of peak usage levels in the late evening and early morning hours. The large, low cost generators that can most efficiently provide electricity cannot be used to satisfy this peaking cycle of demand because they cannot practically be turned down or off in low use hours. Providing price incentives for consumers to run clothesdryers and dishwashers at off-peak hours would allow electric suppliers to get considerably more mileage out of existing plants, and would also allow for efficient expansion.

Flexibility in pricing is hampered, however, by the mechanical meters traditionally used by utilities to measure customer consumption. Such meters measure only customers' kilowatt-hour consumption for a monthly billing period, and do not record the time of day when they consume the power or its hourly cost. By contrast, certain large industrial customers currently have more advanced meters that measure electricity on a 15-minute interval basis; i.e., time-sensitive meters. These customers are charged, in part, based on their time of use. Such meters are not generally installed by electric utilities for residential or smaller commercial customers. If customers are charged the same rate at 5:00 p.m. as at 5:00 a.m., they are not 
going to be particularly concerned about when they operate their water heaters, washers, dryers, computers, and television sets, much less their industries, stores, or offices. If we continue to build power plants to meet peak periods without replacing our metering system and without charging customers based on their time of use, we will not give customers the opportunity to respond to changes in the cost of electricity by shifting their consumption.

Although the costs involved in installing time-sensitive meters are significant, the incentives in the Act for efficiency efforts and building new power plants and transmission lines have high monetary and environmental costs. Adopting time-sensitive pricing programs for all electric consumers, residential as well as commercial, would create a market environment that would produce efficiencies and control demand with less need for government intervention and subsidies. Taking time to further study the issue, rather than extending tax credits and other incentives to "smart metering" now, ensures only one thing - another missed opportunity to reduce US energy demand.

\section{Edward L Flippen}

Partner, McGuireWoods LLP; Lecturer in Law at the University of Virginia School of Law; Honorary Senior Research Fellow at the University College, London Faculty of Laws (contact information: eflippen@mcguirewoods.com) 